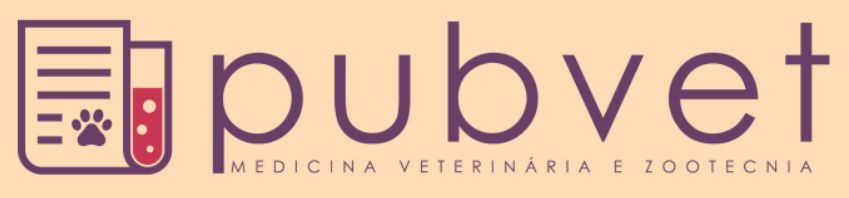

HTTP://DX.DOI.ORG/10.22256/PUBVET.V11N1.82-86

\title{
Carcinoma de células de transição de bexiga em cão: Relato de caso
}

\author{
Sara Almeida Telles ${ }^{1 *}$, Rodrigo Casemiro Pinto Monteiro² ${ }^{\text {, Fábio Miguéis Corrêa }}{ }^{3}$, Paula \\ Zagato Urbani Calvo ${ }^{4}$, Ana Paula Lopes de Moraes Oliveira ${ }^{5}$
}

${ }^{1}$ Aluna de Medicina Veterinária, Universidade Anhanguera de São Paulo - UniAn-ABC, Brasil. E-mail: sariinhatelles@hotmail.com

${ }^{2}$ Orientador Professor de Patologia Cirúrgica e Técnica Cirúrgica da Universidade Anhanguera de São Paulo -UniAn-ABC, Brasil.E-mail: rocasen_@hotmail.com

${ }^{3}$ Co-orientador - CRMV-SP 26696, médico veterinário, especialista em cirurgia da Universidade Anhanguera de São PauloUniAn-ABC, Brasil.

${ }^{4}$ CRMV-SP 29447. Médica Veterinária contratada do setor de Anestesiologia da Universidade Anhanguera de São Paulo UniAn-ABC, Brasil.

${ }^{5}$ CRMV-SP 24.866. Médica veterinária contratada do setor de imagenologia da Universidade Anhanguera de São Paulo UniAn-ABC, Brasil.

*Autor para correspondência

RESUMO. O carcinoma de células de transição (CCT) é a neoplasia de bexiga mais comum no cão, sendo mais frequente em cães idosos e no gênero feminino, compreendendo cerca de $75-90 \%$ dos tumores epiteliais de bexiga. O local mais comumente observado é no trígono vesical, e por isso o tratamento cirúrgico é paliativo. A sua etiologia pode ser considerada multifatorial e os sinais clínicos são hematúria, polaquiúria e disúria, os quais são típicos de infecção urinária, sendo assim, podendo ser confundidos. O diagnóstico só pode ser considerado definitivo após o resultado da análise histopatológica, entretanto através de exames de ultrassonografia, por exemplo, as neoplasias são uma suspeita. $\mathrm{O}$ prognóstico é ruim, onde essa neoplasia é considerada com um baixo potencial de cura e alto índice de mortalidade, e assim despertando interesse demasiado em encontrar possíveis tipos de prevenção, diagnóstico precoce e novos tratamentos. O presente trabalho teve como objetivo relatar um caso de um cão com CCT, expondo a forma de diagnóstico definitivo, que foi por exame histopatológico após cistectomia parcial de bexiga, e o tratamento do mesmo através de sessões de quimioterapia com carboplatina associado ao uso contínuo de piroxicam. Infelizmente após duas sessões o proprietário do animal se ausentou, impossibilitando uma continuidade no tratamento.

Palavras chave: Bexiga, cães, carcinoma

\section{The transitional cell carcinoma of urinary bladder in dog: Case report}

ABSTRACT. The transitional cell carcinoma (TCC) is the most common bladder neoplasia in dogs. It's more frequent in elderly female ones and represents $75-90 \%$ of the bladder epithelial tumors. It generally occurs in the vesical trigone, therefore the treatment is palliative. Its etiology can be considered multifactorial and among the clinical signs are hematuria, polyuria and dysuria - which can be wrongly diagnosed as urinary infection as those are typical signs of this disease. The definitive diagnosis can only be considered after the histopathological analysis' result, however the ultrasonography exams, for example, can detect a neoplasia suspicion. The prognostic for neoplasia is bad, since it has a low potential for cure and a high level of mortality, so that it arises great interest in finding new possible ways of prevention, early diagnosis and new treatments. The present work aims to report a case of a dog with TCC, exposing how the definitive diagnosis was done by the histopathological exam after a bladder partial cystectomy, and its chemotherapy sessions 
with carboplatin associated with the continued use of piroxicam treatment. Unfortunately after two sessions the owner became absent, making it impossible to continue with the treatment.

Keywords: Bladder, carcinoma, dog

\section{Carcinoma de células transicionales de la vejiga en perro: Reporte de} un caso

RESUMEN. El carcinoma de células de transición (CCT) es la neoplasia de vejiga más común en perros, siendo frecuente en animales más viejos y del género femenino, comprendiendo cerca de $75-90 \%$ de los tumores epiteliales de vejiga. El local comúnmente observado es el trígono vesical, y por eso el tratamiento quirúrgico es paliativo. Su etiología puede ser considerada multifactorial y los signos clínicos son hematuria, polaquiuria y disuria, los cuales son típicos de infección urinaria, Justamente por eso, pueden ser confundidos. El diagnóstico sólo puede ser considerado definitivo con el resultado de análisis histopatológica, sin embargo, a través de exámenes de ultrasonografía, por ejemplo, las neoplasias son una sospecha. El pronóstico es reservado, esa neoplasia es considerada con bajo potencial de cura y alto índice de mortalidad, despertando así el interés en encontrar posibles tipos de prevención, diagnóstico precoz y nuevos tratamientos. El presente trabajo tuvo como objetivo relatar el caso de un perro con CCT, exponiendo la forma de diagnóstico definitivo, que fue por examen histopatológico después de la cistectomía parcial de vejiga, y el tratamiento del mismo a través de sesiones de quimioterapia con carboplatina asociado al uso continuo de piroxicam. Infelizmente después de dos sesiones el propietario del animal se ausentó, imposibilitando la continuidad del tratamiento.

Palabras clave: Vejiga, perros, carcinoma

\section{Introdução}

As neoplasias da vesícula urinária são incomuns nos cães e ocorrem em menos de $1 \%$ de todas as malignidades descritas nesta espécie (Zachary et al., 2012, Ettinger and Feldman, 2004). As neoplasias vesicais primárias são representadas principalmente pelo carcinoma de células de transição (CCT), correspondendo à 7590\% dos tumores epiteliais da bexiga (Inkelmann et al., 2011). Os tumores de menores frequências são o carcinoma de células escamosas, o adenocarcinoma, o carcinoma indiferenciado, o rabdomiossarcoma e outros tumores mesenquimais. A maior ocorrência de tumores da bexiga foram em cães com média de 10 anos de idade, e a relação fêmea:macho foi de 1,95:1 (Ettinger and Feldman, 2004).

A etiologia desta doença inclui fatores ambientais como o uso de inseticidas derivados do petróleo, tratamento com ciclofosfamida, exposição do uroepitélio vesical a carcinógenos presentes na urina como os derivados do metabolismo do triptofano (ácido indolacético, um tipo de fitohormônio, e a estricnina, um tipo de alcalóide indolólico), fatores relacionados ao próprio animal, como a obesidade (Ettinger and
Feldman, 2004), exposição a áreas úmidas pulverizadas com substâncias químicas contra mosquitos, ambientes com alta atividade industrial, gênero feminino, obesidade e raça. A retenção de urina na bexiga e a exposição mais prolongada do epitélio a carcinógenos resultam em maior incidência de tumores na bexiga urinária. Muitas substâncias químicas, incluindo os compostos intermediários de corantes de anilina, hidrocarbonetos aromáticos e metabólitos de triptofano, foram associadas experimental ou epidemiologicamente à indução de neoplasias urinárias. Tumores espontâneos ou quimicamente induzidos progridem através de uma série de estágios histológicos de hiperplasia, metaplasia escamosa, papiloma, adenoma, displasia, carcinoma in situ a carcinoma (Zachary et al., 2012). A vesícula urinária pode ser dividida em colo (que se conecta com a uretra), corpo e vértice cranial. A área compreendida entre os dois meatos ureterais e o início da uretra é conhecida como trígono (trigonum vesicae) (Feitosa, 2014), aparentemente apresenta uma origem diferente do restante da parede da bexiga e acredita-se que apresente sensibilidade aumentada (Dyce et al., 2004). Geralmente esta neoplasia se inicia no trígono e se estende para o corpo vesical (Daleck 
et al., 2008). A bexiga tem um epitélio do tipo transicional (Dyce et al., 2004). Os carcinomas das células transicionais são compostos de epitélio transicional anaplásico a pleomórfico. Metástases dos carcinomas da bexiga urinária são encontradas com maior frequência nos linfonodos regionais adjacentes à bifurcação da aorta, incluindo os linfonodos inguinal profundo, ilíaco medial e sacral. Outros locais com potencial de metástases incluem o pulmão e os rins, e mais tardiamente outros órgãos parenquimatosos (Zachary et al., 2012).

Segundo Henry (2007), a urinálise dificilmente revela a presença de células neoplásicas, mas é útil na detecção de hematúria, leucocitúria e presença de bactérias associadas ao quadro. Técnicas especiais de lavagem vesical e citocentrifugação com coloração específica do material podem ser úteis no diagnóstico. A cistografia de contraste e a ultrassonografia são exames indispensáveis para o diagnóstico, porém a confirmação diagnóstica é realizada pelo exame histopatológico e a amostra pode ser obtida por cistoscopia ou laparotomia exploratória.

$\mathrm{O}$ tratamento varia de acordo com o tamanho e localização tumoral e geralmente inclui a remoção cirúrgica seguida de quimioterapia com agente único como a cisplatina, carboplatina, mitoxantrona, actinomicina D ou doxorrubicina (Daleck et al., 2008).

\section{Relato de caso}

Foi atendido no Hospital Veterinário Universitário da Universidade Anhanguera um cão, macho, sem raça definida, de 14 anos de idade, castrado, pesando $7,1 \mathrm{~kg}$, com sinais de hematúria há duas semanas e histórico de cistite.

No exame clínico foram observadas mucosas oral e ocular normocoradas, hidratação adequada, linfonodos normais, frequência cardíaca normofonética regulares sem sopro, campos pulmonares sem alterações, e não teve sensibilidade dolorosa na palpação abdominal. A princípio foram solicitados os seguintes exames complementares: hemograma, uréia, creatinina, fosfatase alcalina, alanina aminotransferase, urinálise (urina tipo I), cultura e antibiograma de urina, ultrassonografia abdominal e radiografia torácica. Por conta do histórico de cistite, a princípio foi realizado tratamento com amoxicilina com clavulanato de potássio na dose de $22 \mathrm{mg} / \mathrm{kg}$ a cada 12 horas e maxicam na dose de $0,1 \mathrm{mg} / \mathrm{kg}$ a cada 24 horas, ambos pela via oral.
No resultado do exame de urina tipo I foi encontrado leucocitúria, sangue oculto, algumas células descamativas globosas e raras de transição. No exame da cultura e antibiograma urinário não houve crescimento bacteriano. No resultado dos exames sanguíneos foram identificados eritrócitos 7,2 milhões $/ \mathrm{mm}^{3}$, hrmoglobina 15,2g/dL, hematócrito $47 \%$, V.C.M $65,28 \mathrm{u}^{3}$, H.C.M 21,11 pg, C.H.C.M 32,34 g/dL, proteína total $7 \mathrm{~g} / \mathrm{dL}$, leucócitos totais $7,20 \mathrm{mil} / \mathrm{mm}^{3}$, segmentados $68 \%$, eosinófilos $5 \%$, linfócitos típicos $20 \%$, monócitos $7 \%$, contagem plaquetária em $450 \mathrm{mil} / \mathrm{mm}^{3}$, uréia $41,43 \mathrm{mg} / \mathrm{dL}$, creatinina $0,91 \mathrm{mg} / \mathrm{dL}$, fosfatase alcalina 50,39 U/L, alanina aminotransferase 65,44 U/L . Após a realização do ultrassom abdominal foi visibilizado a presença de estrutura isoecogênica e pedunculada à parede, irregular, medindo aproximadamente $2,7 \mathrm{~cm} \times 1,5 \mathrm{~cm}$ (Figura 1).

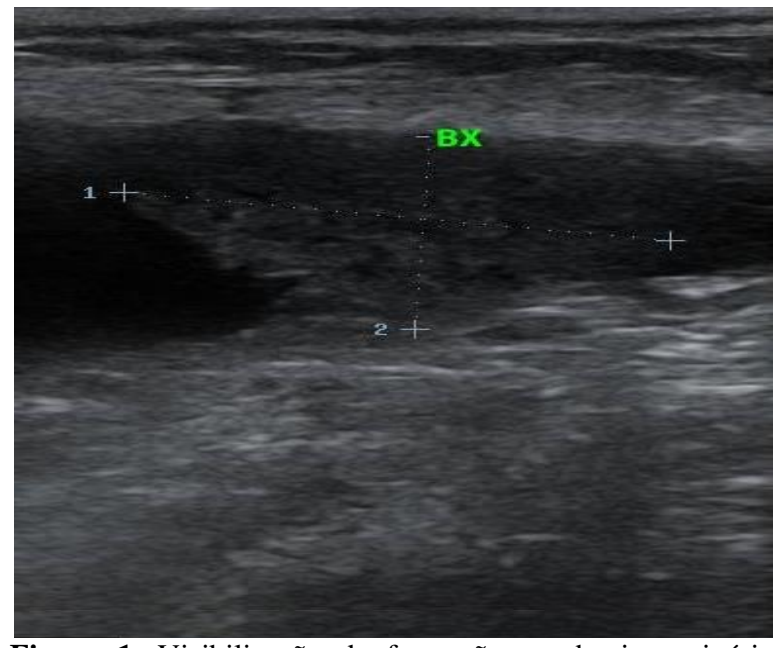

Figura 1. Visibilização de formação em bexiga urinária através do ultrassom abdominal. Fonte: Hospital Veterinário Anhanguera ABC.

Ao exame radiográfico de tórax os campos pulmonares foram visualizados dentro dos padrões de normalidade. Com suspeita de neoformação ou pólipo em bexiga urinária, o paciente foi encaminhado para cirurgia de cistotomia/cistectomia.

Durante o procedimento cirúrgico foi exteriorizado e incisado a bexiga, observado formação pedunculada, irregular e ulcerada aderida a parede (Figura 2), que posteriormente foi removida (Figura 3) e enviada para análise histopatológica. Foram aplicados no pósoperatório imediato amoxicilina com clavulanato de potássio $22 \mathrm{mg} / \mathrm{kg}$ através da via subcutânea, meloxicam $0,1 \mathrm{mg} / \mathrm{kg}$ através da via subcutânea, cloridrato de tramadol $2 \mathrm{mg} / \mathrm{kg}$ através da via intravenosa. Prescrito tratamento oral em casa 
com enrofloxacino $5 \mathrm{mg} / \mathrm{kg}$ a cada 12 horas durante 15 dias, amoxicilina com clavulanato de potássio $22 \mathrm{mg} / \mathrm{kg}$ a cada 12 horas durante 10 dias, meloxicam $0,1 \mathrm{mg} / \mathrm{kg}$ a cada 24 horas durante 2 dias, omeprazol $1 \mathrm{mg} / \mathrm{kg}$ a cada 12 horas durante 10 dias, cloridrato de tramadol $3 \mathrm{mg} / \mathrm{kg}$ a cada 8 horas durante 3 dias, dipirona $25 \mathrm{mg} / \mathrm{kg}$ a cada 8 horas durante 3 dias e limpeza da ferida cirúrgica com clorexidine.

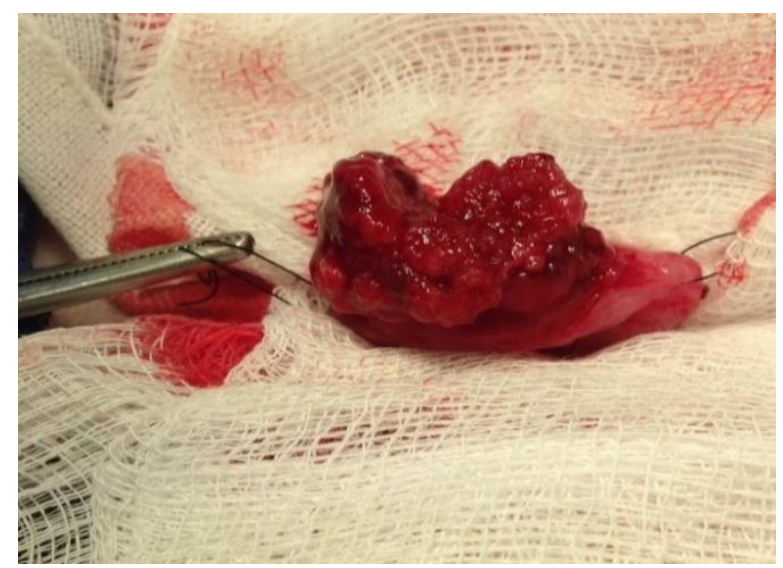

Figura 2. Formação na parede da vesícula urinária observada no trans-operatório. Fonte: Hospital Veterinário Anhanguera $\mathrm{ABC}$.

De acordo com o resultado do exame histopatológico a formação se tratava de Carcinoma papilar infiltrativo de células de transição, com infiltração de submucosa e porção superficial da parede muscular. Após esta confirmação, foi indicado tratamento com quimioterapia com carboplatina na dose de 300 $\mathrm{mg} / \mathrm{m}^{2}$, piroxican $0,3 \mathrm{mg} / \mathrm{kg}$ a cada 24 horas e ranitidina $2 \mathrm{mg} / \mathrm{kg}$ a cada 12 horas. Infelizmente a proprietária realizou duas aplicações de quimioterapia e se ausentou, impossibilitando a continuação do tratamento.

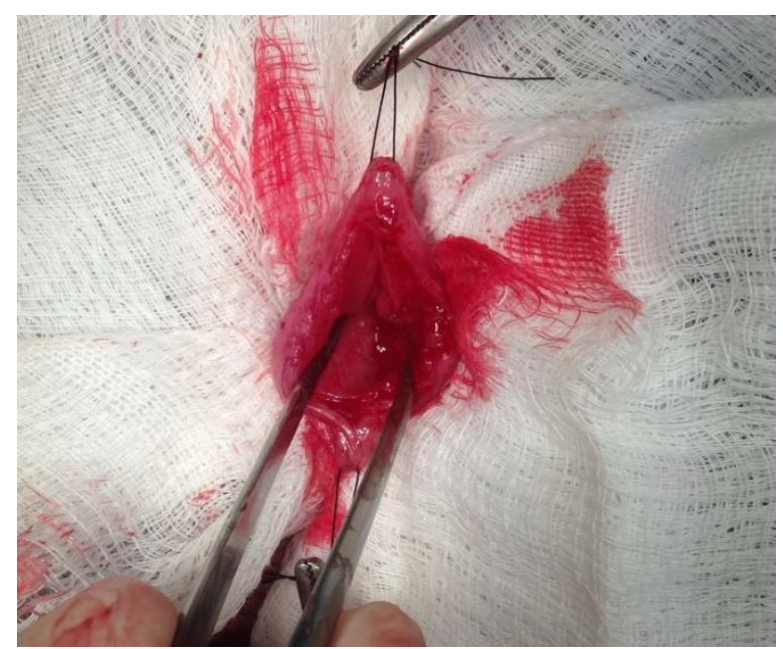

Figura 3. Aspecto da bexiga urinária após retirada de formação. Fonte: Hospital Veterinário Anhanguera ABC.

\section{Resultados e discussão}

As neoplasias vesicais primárias são representadas principalmente pelo carcinoma de células de transição (CCT), correspondendo à 7590\% dos tumores epiteliais da bexiga (Inkelmann et al., 2011). De acordo com Ettinger and Feldman (2004) a maior ocorrência de tumores da bexiga foram em cães com média de 10 anos de idade, e a relação fêmea:macho foi de 1,95:1. Assim como o paciente relatado em nosso caso que já era idoso, porém ocorreu em um animal do gênero masculino, onde a prevalência é menor em relação ao gênero feminino.

A etiologia desta doença inclui fatores ambientais, tratamento com ciclofosfamida, exposição do uroepitélio vesical a carcinógenos presentes na urina como os derivados do metabolismo do triptofano, fatores relacionados ao próprio animal(Ettinger and Feldman, 2004), exposição a áreas úmidas e contaminadas com substâncias químicas, gênero feminino, obesidade e raça. A retenção de urina na bexiga e a exposição mais prolongada do epitélio a carcinógenos resultam em maior incidência de tumores na bexiga urinária (Zachary et al., 2012).

Daleck et al. (2008) descrevem que geralmente esta neoplasia se inicia no trígono e se estende para o corpo vesical, porém no paciente relatado não houve envolvimento do trígono vesical, fato importante para o tratamento, possibilitando a remoção completa da neoformação.

Metástases dos carcinomas da bexiga urinária são encontradas com maior frequência nos linfonodos regionais adjacentes à bifurcação da aorta, incluindo os linfonodos inguinal profundo, ilíaco medial e sacral. Outros locais com potencial de metástases incluem o pulmão e os rins, e mais tardiamente outros órgãos parenquimatosos (Zachary et al., 2012). Até o presente momento não foram identificados formações metastáticas em nosso paciente.

Segundo Henry (2007) a urinálise é útil na detecção de hematúria, leucocitúria e presença de bactérias associadas ao quadro. Técnicas especiais de lavagem vesical e citocentrifugação com coloração específica do material podem ser úteis no diagnóstico. A cistografia de contraste e a ultrassonografia são exames indispensáveis para o diagnóstico, porém a confirmação diagnóstica é realizada pelo exame histopatológico e a amostra pode ser obtida por cistoscopia ou laparotomia exploratória. No paciente descrito não foram 
realizados os exames descritos anteriormente e o mesmo foi encaminhado diretamente para o procedimento cirúrgico de cistotomia e cistectomia, sendo possível a realização histopatológica através da amostra obtida.

De acordo com Daleck et al. (2008) o tratamento varia de acordo com o tamanho e localização tumoral e geralmente inclui a remoção cirúrgica seguida de quimioterapia com agente único como a cisplatina, carboplatina, mitoxantrona, actinomicina $\mathrm{D}$ ou doxorrubicina. Optamos pela realização de carboplatina na dose de $300 \mathrm{mg} / \mathrm{m}^{2}$ e piroxican $0,3 \mathrm{mg} / \mathrm{kg}$ a cada 24 horas, mas o proprietário se ausentou após a realização da segunda quimioterapia, não sendo possível avaliar a resposta ao tratamento.

\section{Conclusão}

Diante da revisão de literatura podemos afirmar que o prognóstico é melhor quando o diagnóstico precoce é realizado, sendo necessário utilizar uma sequência de procedimentos e protocolos como tratamento para conseguir uma maior sobrevida. $\mathrm{O}$ tratamento realizado a princípio promoveu conforto ao paciente, que retornou a sua vida naturalmente, sem apresentar sintomas de disúria, polaquiuria e hematúria. Não existindo um tratamento curativo, é de extrema importância não desistir enquanto houver qualidade de vida.

\section{Referências bibliográficas}

Daleck, C. R., De Nardi, A. B., Rodigheri, S. M. \& Motta, F. R. 2008. Neoplasia do sistema urinário. Roca, São Paulo.
Dyce, K. M., Wensing, C. J. G. \& Sack, W. O. 2004. Tratado de anatomia veterinária. Elsevier Brasil, São Paulo.

Ettinger, S. \& Feldman, E. 2004. Tratado de medicina interna veterinária: doenças do cão e do gato. Guanabara Koogan, Rio de Janeiro.

Feitosa, F. L. F. 2014. Semiologia veterinária: A arte do diagnóstico. Grupo Gen-Editora Roca Ltda., São Paulo.

Henry, C. J. 2007. Transitional cell carcinoma. . Proceedings of the $32^{\circ}$ World Small Animal Veterinary Association. Wsava, Sydney.

Inkelmann, M. A., Kommers, G. D., Fighera, R. A., Irigoyen, L. F., Barros, C. S., Silveira, I. P. \& Trost, M. E. 2011. Neoplasmas do sistema urinário em 113 cães. Pesquisa Veterinaria Brasileira, 31, 1102-1107.

Zachary, J. F., McGavin, D. \& McGavin, M. D. 2012. Bases da patologia em veterinária. Elsevier Brasil.

\section{Article History:}

Received 7 October 2016

Accepted 3 November 2016

Available on line 25 November 2016

License information: This is an open-access article distributed under the terms of the Creative Commons Attribution License 4.0, which permits unrestricted use, distribution, and reproduction in any medium, provided the original work is properly cited. 